\title{
O desolador cenário migratório do Triângulo Norte da América Central: limites e perspectivas no âmbito humanitário ${ }^{1}$
}

\author{
Joseane Mariéle Schuck Pinto \\ Recebido em maio de 2019 \\ Aceito em outubro de 2019
}

\begin{abstract}
RESUMO
O presente estudo propõe uma análise sobre a denominada caravana de migrantes, originária do Triângulo Norte da América Central, composto por El Salvador, Honduras e Guatemala, que testemunha uma das maiores crises humanitárias do século XXI. Os fluxos migratórios, sobretudo de menores desacompanhados, caracterizam-se por deslocados forçados, devendo ser reconhecidos como refugiados e não migrantes econômicos, como vem ocorrendo na prática nas fronteiras de destino, pelo México. $\mathrm{O}$ objeto de estudo se utilizará do referencial teórico do sociólogo Manuel Castells para pensar a influência dos sistemas de redes interligados que geram o processo de violência que acomete ao TNAC, e do filósofo Giorgio Agamben, na medida em que as vidas dos nacionais dos países em análise se encontram desprovidos de proteção e direitos. A modalidade de pesquisa é o estudo qualitativo, por meio da técnica de análise documental nacional e internacional, especialmente artigos de periódicos internacionais especializados sobre o tema. Evidencia-se que não há consenso sobre as bases políticas relacionadas à migração dos países de destino, altamente restritivas e punitivas, o que agrava a crise humanitária.
\end{abstract}

Palavras-chave: Auxílio humanitário; Proteção; Refugiados; Triângulo Norte da América Central.

\section{The bleak migratory landscape of the Northern Triangle of Central America: humanitarian boundaries and perspectives}

\begin{abstract}
The present study proposes an analysis of the so-called caravan of migrants, originating from the Northern Triangle of Central America, composed by El Salvador, Honduras and Guatemala, which witnesses one of the largest humanitarian crises of the 21st century. Migration flows, especially from unaccompanied minors, are characterized by forced displaced persons and must be recognized as refugees and nonmigrant economics, as has been happening in Mexico at destination borders. The object of study will use the theoretical framework of sociologist Manuel Castells to think about the influence of interconnected network systems that generate the process of violence that affects the TNAC, and the philosopher Giorgio Agamben, as the lives of nationals of countries in analysis are devoid of protection and rights. The research modality is the qualitative study, through the technique of national and international document analysis, especially articles from international journals specialized on the subject. It is evident that there is no consensus on the political bases related to the migration of destination countries, highly restrictive and punitive, which aggravates the humanitarian crisis.
\end{abstract}

${ }^{1}$ Destaca-se que uma primeira versão do texto foi apresentada na X edição do Seminário Nacional Sociologia \& Política América Latina hoje: rupturas e continuidades GT 11 - Migrações Internacionais, fronteiras e novas diásporas.

${ }^{2}$ Doutoranda e Mestra pelo Programa de Pós-Graduação em Ciências Sociais - UNISINOS. Especialista em Relações Internacionais e Diplomacia pela mesma instituição. Advogada e professora universitária, bolsista CAPES. E-mail: joseane.ms@terra.com.br. 
Keywords: Humanitarian aid; Protection; Refugees; Northern Triangle of Central America.

\section{Introdução}

\section{Os deslocamentos forçados no mundo global contemporâneo têm se intensificado,}

sobretudo nas Américas. Na América do Sul, com o caso emblemático da Venezuela3, responsável por cerca de 3,4 milhões de solicitações de refúgio no mundo, de acordo com os dados apurados pelo Alto Comissariado das Nações Unidas para Refugiados (ACNUR) e Organização Internacional pra Migrações (OIM) ${ }^{4}$. No entanto, não menos importante está o desolador cenário migratório do chamado Triângulo Norte da América Central, composto por El Salvador, Honduras e Guatemala, implicando reflexos no âmbito do Direito Internacional, das Relações Internacionais e das Ciências Sociais. Neste contexto, há um significativo deslocamento forçado, incluindo um elevado número de menores desacompanhados, os quais são compelidos a deixarem seus países em decorrência da extrema violência urbana e dos reflexos causados no sistema social.

Nos últimos dois anos, o ACNUR descreve a região como a mais violenta do mundo fora de uma zona de conflito. A extrema violência generalizada é responsável pelo crescente aumento do fluxo migratório ${ }^{5}$ e consequente deslocamento forçado dos nacionais desses países. Não obstante o grave panorama securitário da região, a

3 Desde 2015, após o presidente Nicolás Maduro perder as eleições parlamentares da Venezuela, parte da população venezuelana começou a emigrar em maiores números para alguns países da América Latina, principalmente Colômbia e Brasil. Pressões internacionais diversas acrescentadas às crises internas do modelo político que vigorou neste país desde o final da década de 1990 culminaram em crises econômicas, sociais e de abastecimento de alimentos. Diante do aumento dos fluxos de venezuelanos atravessando a fronteira e solicitando refúgio no Brasil, em fevereiro de 2017 o Conselho Nacional de Imigração editou a Resolução Normativa № 126 , que favoreceu a regularização da imigração venezuelana no país. PolicyPaper - Imigração e Desenvolvimento. Disponível em: http://dapp.fgv.br/wpcontent/uploads/2018/o3/Desafio-migrato\%CC\%81rio-Roraima-policy-paper.pdf. Acesso em Abril de 2019 .

4 UNHCR/ACNUR. Disponível em: https://www.acnur.org/portugues/2019/o2/25/numero-derefugiados-e-migrantes-da-venezuela-no-mundo-atinge-34-milhoes/. Acesso em abril de 2019.

${ }^{5}$ A migração conceitua-se pelo movimento de uma pessoa ou um grupo de pessoas, seja através de uma fronteira internacional, ou dentro de um Estado. É um movimento da população, abrangendo qualquer tipo de movimento de pessoas, independentemente da sua duração, composição e causas; que inclui a migração de refugiados, pessoas deslocadas, migrantes econômicos, apátridas, pessoas que se deslocam para outros fins, incluindo o reagrupamento familiar, assim como àqueles que necessitam deixar seu país de origem por razões ambientais ou pelo acometimento de catástrofes naturais (OIM, 2011). 
compreensão equivocada de que tais fluxos são basicamente de caráter econômico, mesmo após as declarações do ACNUR, no sentido de caracterizar a região como local de grave crise humanitária e aqueles que tentam chegar ao norte através do maior corredor migratório do mundo devem de fato ser considerados refugiados, estando assim sob a proteção das diretrizes da Declaração de Cartagena 1984, que à época ampliou o escopo da definição de refugiado e inseriu as pessoas que sofrem com a violência generalizada, considerando-as como refugiados.

O presente estudo propõe uma análise abrangente acerca dessa problemática, a partir do olhar das Ciências Sociais, pois para a compreensão do fenômeno social se faz relevante para compreender a migração originada da região analisada. Neste sentido, percebe-se que a corrupção nos países pertencentes ao TNAC permitiu que redes de crime organizado internacional adentrassem as instituições estatais restringindo à capacidade dos governos centro-americanos de manter direitos humanos básicos a população. Paralelamente a escalada de autoritarismo e violência na América Central, EUA e México sendo os dois principais destinos dos que fogem da violência endureceram suas políticas migratórias, reforçaram o policiamento em suas fronteiras e consequentemente aumentaram o número de detenções e deportações.

O objeto de estudo, ancorado nas questões de mobilidade humana e suas implicações no cenário global, se utilizará do referencial teórico do sociólogo Manuel Castells, sendo possível pensar a influência dos sistemas de redes interligados e que geram o processo de violência que acomete ao TNAC. Do mesmo modo, Giorgio Agamben seu estudo sobre o estado de exceção, corrobora com a análise proposta no presente artigo, na medida em que as vidas dos nacionais dos países em questão se encontram em condição de mera vida nua, pois estão desprovidos de proteção e direitos políticos advindos do Estado-nação. De forma incipiente, vez que a pesquisa se encontra em estágio inicial, é possível perceber que o atual cenário internacional se encontra abalado por não haver consenso sobre as bases políticas relacionadas à migração dos países de destino, que por sua vez são restritivas e punitivas, corroborando para o agravamento de uma severa crise humanitária.

O levantamento de dados será realizado através de coleta bibliográfica e documental (fontes secundárias), sendo fundamental que a pesquisa integre a consulta 
a dados e publicações oficiais de atores não governamentais envolvidos com o auxílio humanitário, como o ACNUR, IOM, Comitê Nacional para Refugiados (CONARE) e Serviço Jesuíta a Migrantes e Refugiados.Em Relação ao tratamento dos dados será interpretativo-descritivo, o que possibilitará a interpretação da realidade que se apresenta de diversas formas. Desse modo, a temática em questão se justifica por sua relevância social, pela urgência em trazer à tona o fenômeno contemporâneo e complexo que é a migração oriunda dos países do TNAC, na medida em que impõe deslocamentos forçados dos nacionais pertencentes aos Estados afetados, bem como a necessidade de repensar para além do auxílio humanitário, visto a necessidade de proteção internacional, por meio do reconhecimento do status de refugiado, reconhecendo o instituto do refúgio como fronteira da cidadania e não como mero mecanismo de controle fronteiriço.

\section{O contexto histórico de deslocamentos do Triângulo Norte da América Central e seus reflexos enquanto fenômeno social}

Trazer à tona a realidade social existente na região do Triângulo Norte da América Central se faz primordial, na medida em que afeta seus nacionais, e por sua vez, impõe implicações em demais Estados que compõe o cenário internacional.A região é responsável pelo significativo aumento de deslocamentos forçados, mais conhecida como "caravana de migrantes", sobretudo elevado número de menoresdesacompanhados e mulheres. Tal fluxo migratório, segundo aponta Sassen resulta do aumento da violência urbana, bem como trata-se de fenômeno novo, na medida em que "crianças e mulheres são impelidas a migrar em razão de um enorme medo porcausa da extrema violência urbana que entrou em erupção nos últimos anos" (2016, p. 31).

A situação interna de El Salvador, Honduras e Guatemala demonstra que a violência é um dos maiores problemas históricos no TNAC. De acordo com Correa (2015, p.83) [...] se no passado recente, movimentos camponeses e facções guerrilheiras eram comumente apontados pelos governos da região como responsáveis por ela, hoje, em boa medida, são as gangues de rua. No entanto, a formação e a expansão desses grupos 
estão diretamente relacionadas à violência de outrora, seja aquela manifestada através da luta armada entre organizações com fins políticos [...]. Esta cenário, corroborado com um forte processo de desigualdades sociais na região do TNAC, que por sua vez gerou a extrema pobreza, entre as décadas de 1970 e 1980, fez com que os nacionais de El Salvador, Honduras e Guatemala deixassem seus países rumo aos EUA, fixando-se em Los Angeles e arredores (DOMÍNGUEZ, 2008, p. 2-3).

Conforme, o levantamento de dados da Comissão Econômica para a América Latina e o Caribe (CEPAL, 2002, p. 106; 145; 177), em 1980, encontravam-se 196.674 indivíduos nos EUA, migrantes da região do TAC. Na década seguinte, a monta atingiu 800.095 migrantes, dos quais 465.433 salvadorenhos, 225.739 guatemaltecos e 108.923 hondurenhos. Neste período, muito antes da era Trump e de suas políticas de fechamento de fronteiras, estes migrantes adentraram território americano de forma indocumentada e permaneceram no local com essa condição.

Nota-se, que a falta de políticas migratórias, no sentido de uma migração segura, regular e ordenada acaba por gerar problemas sociais, visto que nem todas as pessoas que migram têm as oportunidades legais de fazê-lo. Muitas são forçadas a deixarem seus territórios e sem a oportunidade de migrarem de forma documentada e acabam recorrendo a contrabandistas de migrantes $^{6}$. Esses atravessadores, com o objetivo de explorar a situação dos migrantes para obtenção de lucro, agem como criminosos ao oferecem os mais variados serviços com elevados custos, como transporte e falsificação de documentos. A prestação de serviços dos criminosos está cada vez mais completa: com controle nas fronteiras nacionais e requisição de vistos. Os criminosos que visam ao lucro aproveitam a oportunidade e contraem o contrabando de migrantes, visto ser uma prática considerada como crime organizado internacional e altamente lucrativo.

As implicações decorrentes da falta de regularização migratória, resultou aos migrantes do TNAC em Los Angeles e arredores um processo de exclusão e discriminação, onde restou a eles a ocupação das áreas periféricas, a falta de emprego, o não acesso a bens públicos, a xenofobia, que por conseguinte fez com que alguns

${ }^{6} \mathrm{O}$ "contrabando de migrantes é um crime que envolve a obtenção de benefício financeiro ou material pela entrada ilegal de uma pessoa num Estado, no qual essa pessoa não seja natural ou residente". UNODC. Disponível em: <http://www.unodc.org/lpo-brazil/pt/trafico-de-pessoas/index.html>. Acesso em abril dezo19. 
passassem a fazer parte de gangues de rua. Sobre a questão (CORREA, 2015, p. 83), nos ensina que [...] alguns passaram a ingressar em gangues de rua existentes nos bairros em que residiam, enquanto outros, decidiram formar seus próprios grupos. São exemplos de cada uma dessas experiências as duas maiores maras atuantes na região atualmente, a dizer, as rivais Barrio 18 (por vezes, referida, também, como Mara 18, Pandilla 18, Calle 18, entre outros) e Mara Salvatrucha 13 (mais conhecida pela sigla MS-13).

No entanto, na década de 1990, em razão do enrijecimento da legislação migratória nos EUA, a exemplo do Ato de Reforma da Imigração Ilegal e da Responsabilidade do Imigrante, os migrantes indocumentados provenientes da região do TNAC foram deportados compulsoriamente para os seus países de origem. Conforme dados do Departamento de Segurança Interna dos EUA, conhecido como Homeland Security, sofreram deportação em torno de 14,5 milhões de pessoas (das mais diversas procedências nacionais), entre os anos de 1991 a 2000 (UNITED STATES DEPARTMENT OF HOMELAND SECURITY, 2012, p. 102).

Dentre eles nacionais de El Salvador, Guatemala e Honduras.Diante deste cenário, a saída compulsória de nacionais dos EUA com retorno aos países do TNAC, segundo análise de Correa, é um fator relevante que corroborou com o aumento e a propagação das gangues de rua em El Salvador, Guatemala e Honduras, embora não seja o único:

\footnotetext{
Percebe-se, por essa trajetória, que os Estados Unidos têm relação direta com a questão das gangues de rua no Triângulo Norte em pelo menos quatro momentos: I) na intervenção nos processos políticos da região na segunda metade do século XX, os quais, entre outros efeitos, resultaram na emigração de muitos indivíduos; II) no insucesso em integrar muitos dos imigrantes salvadorenhos, guatemaltecos e hondurenhos à sociedade estadunidense, resultando em sua submissão a condições adversas de sobrevivência e favorecendo, consequentemente, a participação de alguns deles em gangues de rua; III) na deportação massiva (ou outras formas de retorno compulsório) de imigrantes, entre eles, membros de gangues; e IV) na cooperação com autoridades locais no combate aos referidos grupos até a atualidade (CORREA, 2015, p. 84).
}

Desse modo, não restam dúvidas que o problema social da migração contemporânea oriunda da região do TNAC, gera implicações na vida daqueles que se deslocam e cruzam a fronteira internacional, uma vez que são decorrentes de um 
fenômeno social histórico na região, e que se agravou na medida em que foi deflagrada a exclusão desses nacionais nos EUA, sendo estereotipados como ilegais, e após com o retorno compulsório desses migrantes, o que pode ter contribuído ou agravado a atual situação vivida na região, e responsável pelos fluxos migratórios contemporâneos, mais uma vez com destino aos EUA.Sobre a questão da expressão “migrante ilegal”, relevante mencionar que nenhum ser humano no mundo pode ser considerado juridicamente ilegal.

Neste sentido, a OIM, atualmente, integrante da Organização das Nações Unidas (ONU) e responsável por dirimir as lacunas existentes nas denominações pertinentes à migração. Dentre elas a conceituação daqueles que se deslocam forçadamente ou de forma voluntária, sem o documento hábil para tanto, ou seja, não possuem o visto para ingressar no país de destino. Tal conduta faz com que sejam considerados migrantes indocumentados ou no máximo a nomenclatura de irregulares. Particularmente, prefiro utilizar o termo indocumentado, haja vista a existência de uma onda conservadora que vem se espraiando pelo cenário internacional, e por sua vez proporciona o acirramento da xenofobia.

O fenômeno denominado “caravana de migrantes”, sofre a influência dos sistemas de redes interligados, ao passo que milhares de homens, mulheres e crianças, essas na sua maioria desacompanhadas, estão caminhando ao norte pelo México em direção aos Estados Unidos, em busca de oportunidades e segurança. Durante o caminho, podem tornar-se vítimas de extorsão cometida por autoridades da segurança e por grupos criminosos, assim como ameaças de roubo, violência sexual e até mesmo morte, alerta o comitê da ONU7.

Nesse sentido, importante destacar Castells (2016), no seu estudo sobre a sociedade em redes, vez que possui estreita relação com a realidade interna nos países do TNAC. Inicialmente, os nacionais sofrem com a violência doméstica, fruto das gangues urbanas que em alguma medida possuem atuação e alcance transnacional. Portanto, se enquadram no sistema de redes proposto pelo autor. Num segundo momento, quando aderem a caravana de migrantes e buscam cruzar as fronteiras,

7 Nações Unidas. Disponível em: https://nacoesunidas.org/protejam-os-direitos-humanos-demigrantes-da-america-central-pedem-comites-da-onu-a-governos/. Acesso em abril de 2019. 
acabam se tornando vítimas da atividade desempenhada pelos “coiotes", ou seja, a expansão e diversificação do cometimento desta prática criminosa transnacional em prol das redes de contrabando de migrantes, integradas ao sistema-mundo e vinculadas a organizações e associações criminosas internacionais. Sobre a questão, destaca-se o relato de um migrante a BBC News Brasil em outubro de 2018: "Em Honduras, temos medo de morrer de fome ou assassinados pelas maras (gangues). Por isso, quando ouvi sobre a caravana de migrantes, decidi deixar tudo (e me juntar a ela)."8

Para Castells "as atividades criminosas e organizações ao estilo da máfia de todo o mundo também se tornaram globais e informacionais, propiciando os meios para o encorajamento de hiperatividade mental e desejo proibido, juntamente com toda e qualquer forma de negócio ilícito procurado por nossas sociedades [...]” (2016, p. 62). Observa-se que tal exame se faz importante, ao passo que a livre circulação de bens, mercadorias e pessoas impulsiona às oportunidades de negócios nos diversos países do mundo, inclusive aqueles relacionados à atividade ilícita, unidos à velocidade no contexto global da evolução tecnológica, dos meios de transporte e comunicação.

Além disso, os integrantes das caranavas de migrantes, é um alvo para atuação dos "coiotes" que os aliciam sabendo que estão se deslocando de forma indocumentada ou irregular. Nesse sentido, a ideia de estado de exceção, de acordo com Agamben, se perfectibiliza, pois o migrante é colocadosob a vontade soberana da rede dos contrabandistas, que por conseguinte passa a controlá-los e regulá-los, reduzindo suas vidas em condição de mera vida nua, pois estão desprovidos de direitos políticos advindos do Estado-nação. No mesmo sentido, o sistema político-jurídico, através do controle biopolítico, acaba por manipular as questões relacionadas à migração e a excluílo, como ator social, das decisões políticas e jurídicas que lhe dizem respeito. Nessa condição, a vida humana se torna frágil, vulnerável e facilmente controlável. Segundo o autor “o ser humano é destituído de toda condição política e reduzido ao estatuto de simples vida nua, na qual a lei é integralmente suspensa, assim como o direito, e a todo

${ }^{8}$ Antonio García é um dos milhares de hondurenhos que estão juntos em uma longa caminhada que tem como destino final os Estados Unidos. O grupo, que hoje soma cerca de 4 mil pessoas, saiu no último sábado de San Pedro Sula, no norte de Honduras, país da América Central, e chegou ontem à fronteira com o México. BBC News Brasil. Disponível em: <https://www.bbc.com/portuguese/internacional-45926416>. Acesso em abril de 2019. 
o momento se está à mercê de um poder incondicional de vida e morte" (2010, p. 16667). O estado de exceção visa sempre o controle (bio)político da vida humana, e ao deixarem forçadamente suas nações acabam não sendo reconhecidos como cidadãos de pleno direito e passam à exposição permanente de abusos e de violência.

Ao demais, vem ao encontro o relatório apurado pela Comissão Econômica para América Latina e Caribe (Cepal, 1999), que relaciona os deslocamentos na América Central com o fenômeno social e os problemas estruturais dos países que compõe a região. Sem dúvida, os fluxos migratórios tiveram grande incremento a partir dos conflitos sociais e políticosocorridos na década de 1980 e 1990 em El Salvador e Guatemala e, anteriormente, na Nicarágua, em 1960-1970, isto é, os deslocamentos gerados como consequência direta desses conflitos. No entanto, na contemporaneidade atingiram um fluxo migratório intenso e diário. Por fim, a transnacionalização laboral e globalização da América Central, no período pós-guerra centro-americano, caracterizado comoa fase que se formou um novo fluxo migratório, impulsionado por uma ausência generalizada de políticas nacionais de desenvolvimento.

\section{A “caravana de migrantes": auxílio humanitário ou mecanismos de proteção a migrantes e refugiados?}

O fluxo migratório oriundo dos países da América Central (TNAC), caracterizase por ser um processo intenso e complexo, onde muitos deslocamentos são compostos por processos migratórios mistos, ou seja, configurados como refugiados e como migrantes econômicos. Porém, independente de seus status migratório a proteção aos direitos humanos dessas pessoas deve ser respeitada pelos Estados.

Sassen afirma que "sob a pressão dos EUA, o México começou a prender e deportar dezenas de milhares de pessoas da América Central muito antes de chegarem à fronteira com os EUA. O que mudou para estes migrantes é o tratamento que eles estão recebendo na fronteira sul do México, que é ainda mais selvagem do que antes" (2016, p. 33). No mesmo sentido, os noticiários veiculam que o chefe do Instituto Nacional de Migração do México, Tonatiuh Guillén, ressaltou “o aumento das deportações do país, dizendo que o México devolveu 15 mil imigrantes nos últimos 30 dias. Ele não especificou 
para onde eles foram deportados, mas a maioria das pessoas que atravessa o México rumo aos EUA é de Guatemala, Honduras e El Salvador, onde os imigrantes dizem estar fugindo da corrupção, da violência das gangues e da pobreza crônica" 9 . Na segunda-feira (22 de abril de 2019), agentes da polícia federal e do INM encurralaram uma caravana integrada por 3 mil imigrantes irregulares, em sua maioria hondurenhos, enquanto andavam por uma estrada no estado de Chiapas, no Sul do país. Algumas pessoas tentaram fugir, enquanto outras foram colocadas em ônibus oficiais. Os detidos, entre os quais há crianças, foram levados a centros de internamento na cidade fronteiriça de Tapachula, enquanto se regulariza a sua situação ${ }^{10}$.

Diante da complexa realidade, o Governo do México, através do Instituto Nacional de Migração, em 23 de abril de 2019, publicou Boletim da política de migração para fornecer ajuda humanitária. Em conferência proferida pelo Ministro do Interior, Olga Sánchez Cordero e pelo Chanceler, Marcelo Ebrard Causaubon, o México pede respeito as suas leis e aceite do registro migratório como condição prévia. Explicaram ainda, que os EUA e México possuem pontos de vista diferentes em matéria migratória, e a visão do governo mexicano tem três eixos fundamentais: a proteção dos direitos humanos, o desenvolvimento econômico e social dos países da região centro-americana e o registro ordenado dos direitos humanos, migrantes que entram no território nacional, como pré-condição para o Governo proteger seus direitos humanos.Destacaram ainda que desde o ano de 2018 houve um comportamento sem precedentes no fluxo migratório centro-americano, especialmente o originado em Honduras e, em menor medida, na Guatemala e em El Salvador. A proporção de mulheres e menores também aumentou sem precedentes. Eles também chegaram ao México em números incomuns, migrantes de outras nações. "Estamos fazendo", disse o Ministro, "tudo o que está nas mãos do governo federal para cuidar dessas pessoas e darlhes atenção humanitária"."É um cenário complexo, não é que não tenha solução, estamos construindo. Na estação migratória há sempre todas as atenções, elas são muito

\footnotetext{
9 Notícia veiculada em 23 de abril de 2019. Disponível em: <https://br.reuters.com/article/topNews/idBRKCN1So1ZT-OBRTP>. Acesso em abril de 2019.

1o O Globo Mundo. Disponível em: <https://oglobo.globo.com/mundo/mexico-endurecepolitica-migratoria-detem-quase-40o-centro-americanos-caminho-dos-estados-unidos-23618686>. Acesso em abril de 2019 .
} 
pressionadas pela capacidade - nós a reconhecemos -, mas são situações que são em grande parte motivadas por esse fluxo anormal. Há um enorme esforço de muitas instituições do Estado, do Governo Federal, até do estado, de apoio alimentar, abrigos, serviços médicos ", afirmou"11.

Percebe-se que a política em relação a migração no México não é clara, tampouco preocupada em auxiliar aos migrantes. Denota-se, outrossim que o governo busca manter a política da boa vizinhança, ao passo que não quer se indispor com o vizinho EUA e seu principal parceiro comercial. Causa, no mínimo estranheza, que na mesma semana, o governo deporta nacionais vindos do TNAC e traz à tona uma nova política com viés humanitária. Contudo, há de referir que o governo do México ao invés de conceder vistos, pretende promover o "cartão de visitante regional", que por sua vez é mais restrito. O cartão limita a mobilidade dos migrantes aos quatro estados do Sul do México e os afasta de seu objetivo de cruzar a fronteira com os EUA.

Embora, a realidade da caravana de migrantes, traga consigo um caráter misto, abrangendo as categorias de migrantes econômicos e de refugiados, não se pode deixar de mencionar que, a partir de um Colóquio organizado em Cartagena em 1984, na Colômbia, chegou-se a elaboração da Declaração de Cartagena sobre os Refugiados, devido aos mais diversos conflitos armados ao longo da década de 1980, tais como: na Nicarágua, em El Salvador e na Guatemala, provocando o deslocamento de mais de dois milhões de pessoas. Do total de refugiados, apenas 150 mil se enquadravam na definição de refugiado da Convenção de 1951, verificou-se que o conceito tradicional não dava conta do fenômeno social da época, proveniente dos conflitos no continente americano, fazendo-se necessária a modificação do que se entende por refugiado. A Declaração de Cartagena, portanto ampliou a definição ao considerar também como "refugiados as pessoas que fugiram de seus países porque sua vida, segurança ou liberdade foram ameaçadas pela violência generalizada, ou agressão estrangeira, conflitos internos,

${ }^{11}$ Instituto Nacional de Migração-Secretaria de Governo do México. Disponível em: <https://www.gob.mx/inm>. Acesso em abril de 2019. Tradução Livre. 
violação massiva dos direitos humanos ou outras circunstâncias que tenham perturbado gravemente a ordem pública” ${ }^{12}$

A Declaração de Cartagena, portanto contribui para a ampliação do conceito de refugiado em casos de violação aos direitos humanos, podendo servir de base para adaptar a normativa internacional à luz das realidades regionais, e se aplicar a política migratória do México.Dessa feita, se estará reconhecendo o instituto do refúgio como fronteira da cidadania e não como mero mecanismo de controle fronteiriço.

O reconhecimento da condição de refugiado por um Estado significa o resultado de um mero gerenciamento, caso a caso, destinado a fixar a fronteira da cidadania em uma condição reconhecida como a do Estatuto do Refugiado. O processo da concessão e reconhecimento de refúgio é o resultado da extensão dos mecanismos de controle fronteiriço estatal, que ao não reconhecer a cidadania torna o refugiado sujeito fronteiriço e de fronteira. Sobre a questão Ruiz-Estramil bem coloca que:

\footnotetext{
El "asilo" se convierte por tanto como unespaciofronterizo, en donde elsujetodesplazado se rerecoloca dentro de una nuevaconceptualización. Este pasodeviene una fronterahabitable por cuanto que supaso no es automático, sino que se realiza mediante um procedimento em el cual se "estudia" la pertinencia de un nuevo reconocimiento para el sujeto. El sujeto que deviene asilado se introduceenunprocedimiento que le definirá por lascarencias de protecciónensu lugar de origen. Fronterizotambién por cuanto que no se trata de unpaso automático, sino que se estudia, se examina lapertinencia de esenuevoreconocimiento para elsujeto (2018, p. 82).
}

Por outro lado, há esforços no sentido de pôr em prática mecanismos sociais aplicados à proteção e a garantia de direitos com alcance internacional aos migrantes e refugiados. Desse modo, a Missão Tripartite, composta pelo Serviço Jesuíta a Migrantes e Refugiados (SJMR), ACNUR e governo brasileiro, representado pelo CONARE, realizada em El Salvador, em abril desse ano, com intuito de fomentar novas estratégias de acolhida no Brasil a serem implementadas pelo Programa de Reassentamento de Refugiados, sendo que serão recebidos como reassentados em maio deste ano no estado

12 Declaração

de Cartagena. Disponível em: <https://www.acnur.org/fileadmin/Documentos/portugues/BD_Legal/Instrumentos_Internacionais/De claracao_de_Cartagena.pdf>. Acesso em abril de 2019. 
do Rio Grande do Sul, 26 salvadorenhos e hondurenhos. Depreende-se, portanto que foi estendido a essas pessoas o status de refugiado ${ }^{13}$.

O Estado com seu aparato normativo não consegue dar conta do fenômeno complexo que envolve a realidade dos novos fluxos migratórios, gerando cada vez mais processos de exclusão. Sobre a exclusão Bauman refere que os migrantes são "produtos rejeitados da globalização” (2005, p. 84). Enquanto “dejetos”, esses seres humanos são indesejáveis à "elite do poder do mundo globalizado" (2005, p. 93). No mesmo sentido, Ruiz-Estramil afirma que a normativa universal em prol dos refugiados não contempla os novos fatos sociais e corrobora com a exclusão dos deslocados forçados, [...] sendo um habitante dos limites, o refugiado sobrevive como um resto [...]" ( 2018 , p. 3).A decisão meramente política ao conceder uma proteção de cunho humanitário, visto que não se enquadram na categoria de refúgio, a exemplo do migrante econômico, ou que por outras razões não querem recorrer a tal procedimento, acaba construindo com o Estado "anfitrião" um jogo de estratégias que possibilitam contextos de um sujeito que se torna consciente das possibilidades entre as quais ele pode se mover. Da mesma forma, o próprio Estado acaba por enfraquecer o instituto do refúgio, se perfectibilizando como mecanismo de controle fronteiriço e criando uma fronteira conceitual.

\section{Considerações Finais}

Migrar é um direito humano, como bem reconhecem os instrumentos internacionais de proteção humana, entretanto perpetuam as contradições impostas entre a lei e a vida humana, eis que a cidadania plena não é estendida a todos. Como bem afirmava Hannah Arendt, o que predominava e continua a predominar no cenário internacional é a carência do "direito de pertencer à determinada comunidade", "direito de pertencer à humanidade", assim como o "direito a ter direitos". (ARENDT, 1990, p. 330). Os migrantes e refugiados que deixam os países do TNAC, portanto não teriam direitos porque não fazem parte e não são membros do de acolhida?

${ }^{13}$ Jesuítas Brasil. Disponível em: <http://www.asav.org.br/sjmr-porto-alegre-marca-presencaem-missao-tripartite-na-america-central/>. Acesso em abril de 2019. 
Diante destas inquietações, em que à vulnerabilidade dos migrantes e refugiados não é reconhecida pelo poder do soberano, cabe a reflexão de se (re) pensar o Estado contemporâneo e sua forma de atuação. A necessidade de pensar a possibilidade de um Estado promotor do desenvolvimento e da inclusão social é fundamental para o fortalecimento da democracia e para a garantia de dignidade humana daqueles que migram e que se encontram na condição de vida nua. Nota-se que a adoção de uma cultura política, ações, estratégias e políticas públicas voltadas à atenção aos migrantes e solicitantes de refúgio é uma questão primordial a ser abordada pelo sistema internacional. De acordo com Agamben o refugiado representa um elemento inquietante na ordem do Estado-nação; a sua condição rompe a identidade entre o humano e o cidadão, e conceito de refugiado tradicional não encontra relação no conceito de "direitos humanos". Além disso, "o humanitário separado do político não pode senão reproduzir o isolamento da vida sacra sobre o qual se baseia a soberania, sendo o paradigma biopolítico para o qual ele não consegue encontrar solução" (2010, p. 130).

\section{Referências}

ACNUR, Tendências Globais sobre refugiados e outras populações de interesse do Acnur. Disponível em: <http://www.acnur.org/portugues/recursos/estatisticas/>. Acesso em abril de 2019 .

AGAMBEN, Giorgio. Homo Sacer. O poder soberano e a vida nua I. Tradução Henrique Burigo, 2 ${ }^{\mathrm{a}}$ ed. Belo Horizonte: Editora UFMG. 2010.

Estado de Exceção; tradução de Iraci D. Poleti. São Paulo: Boitempo, 2004.

ALVAREZ, Marcos César e SALLA, Fernando. Estado-nação, fronteiras, margens. Redesenhando os espaços fronteiriços no Brasil contemporâneo. Civitas: Porto Alegre. v. 1,3 n. 1, p. 9-26, jan.-abr. 2013.

ARENDT, Hannah. Origens do totalitarismo - Antissemitismo, Imperialismo, Totalitarismo. Tradução Roberto Raposo. Companhia das Letras, 1990.

BAUMAN, Zygmunt.Vidas Desperdiçadas. Rio de Janeiro, Jorge Zahar Editor: 2005. BBC News Brasil. Disponível em: <https://www.bbc.com/portuguese/internacional45926416>. Acesso em abril de 2019. 
CASTELLS, Manuel. A sociedade em rede. 17 ed. São Paulo: Paz e Terra, 2016.

CEPAL (Comisión Económica para América Latina y el Caribe). Informes Nacionales sobre Migración Internacional en Países de Centroamérica. Taller de capacitación para elanálisis de 161 informacióncensal sobre migración internacional en América Central. Serie Seminarios y Conferencias, 24. Santiago: Naciones Unidas, 2002.

CEPAL. Migración y desarrolloen América del Norte y Centroamérica: una visiónsintética. Migración Internacional: Série Población y Desarrollo, $\mathrm{n}^{\circ}{ }^{1}$. Santiago de Chile,1999.

CORREA, Paulo Mortari Araujo. As maras e pandillas no Triângulo Norte da América Central e a atuação dos Estados Unidos em seu combate. 2015. $180 \mathrm{f}$. Dissertação (Mestrado em Relações Internacionais) - Pontifícia Universidade Católica de São Paulo, São Paulo, 2015. Disponível em: https://tede2.pucsp.br/handle/handle/17436. Acesso em abril de 2019.

Declaração de Cartagena. Disponível em:<https://www.acnur.org/fileadmin/Documentos/portugues/BD_Legal/Instrumento s_Internacionais/Declaracao_de_Cartagena.pdf >. Acesso em abril de 2019.

DOMÍNGUEZ, Alfredo Nateras. Etnografías al Límite: espacios de lasviolencias y lasmuertesensujetostransnacionales. Revista E-Compós. Associação Nacional dos Programas de Pós-Graduação em Comunicação. Brasília, v.11, n.3, set./dez. 2008.

IOM.Glossário sobre Migração, Lei das Migrações Internacionais, Série No. 25, 2011. Tradução livre.

Instituto Nacional de Migração-Secretaria de Governo do México. Disponível em: https://www.gob.mx/inm. Acesso em abril de 2019.

Jesuítas Brasil. Disponível em: http://www.asav.org.br/sjmr-porto-alegre-marcapresenca-em-missao-tripartite-na-america-central/. Acesso em abril de 2019.

Nações Unidas. Disponível em: https://nacoesunidas.org/protejam-os-direitoshumanos-de-migrantes-da-america-central-pedem-comites-da-onu-agovernos/.Acesso em abril de 2019.

RUIZ-ESTRAMIL, Ivana. (2018). El refugiado: sujeto de frontera, sujetofronterizo. Iberoamérica Social: revistared de estudiossociales IX, pp. 77 - 93. Recuperado en<https://iberoamericasocial.com/refugiado-subjeto-frontera-subjeto-borderizo $>$.

Acesso em abril de 2019. 
SASSEN, Saskia, "Três migrações emergentes: uma mudança histórica", SUR 23 (2016). Disponível em: http://sur.conectas.org/tres-migracoes-emergentes-uma-mudancahistorica/. Acesso em abril de 2019.

UNITED STATES DEPARTMENT OF THE TREASURY. TreasurySanctionsLatin American Criminal Organizations, 2012. Disponível em: http://www.treasury.gov/press-center/pressreleases/Pages/tg1733.aspx. Acesso em abril de 2019. 